\title{
Contemporary Overstimulation in the Age of Information: The Blurring of The Personal and Political in Ben Lerner's 10:04 and Olivia Laing's Crudo
}

\section{Amal Alshamsi \\ University of Edinburgh}

\begin{abstract}
Olivia Laing's Crudo and Ben Lerner's 10:04 depict the constant interruption of the personal by global concerns and politics. Both novels are concerned with the decision between the personal and the global selves, and how these impending social, environmental, or political crises cloud the narrators' minds. Their structure reflects this confusion and dislocation of the personal self, as the novels contain non-sequiturs, urban noise, and unrelated sections that have been pieced together deliberately. These novels capture the overstimulation of contemporary life and mass media or the information age while trying to navigate how art can reflect that and encapsulate a reality that is at once absurd and (seemingly) not contrived. While the barrier between the personal and global collapses, Lerner and Laing find a space in between where a realist yet raw (or 'crudo') retelling of contemporary media-addled experience can be represented. This essay incorporates commentary on how these texts engage with the idea of the troubled personal and the demise of individuality in the light of 21 st-century overstimulation.
\end{abstract}

\section{Keywords}

Realist Fiction, Contemporary Moment, Overstimulation 


\title{
Contemporary Overstimulation in the Age of Information: The Blurring of The Personal and Political in Ben Lerner's 10:04 and Olivia Laing's Crudo
}

\begin{abstract}
Amal Alshamsi

\section{Introduction}

Realist fiction set within the contemporary moment constantly grapples with portraying media-saturated lives as the form of the novel itself seems incompatible with the lived experience of being constantly connected. To exist within the present society is to be surrounded by the omnipresent voices of the media that overload neural synapses, leaving scarcely any time for reflection before the next big crisis is brought to public attention. Hence, writers set on the task of writing contemporary realism are met with the challenge of integrating the fast-paced, unpredictable influx of stimuli within the novel's contemplative and deliberate medium. Ben Lerner's 10:04 (2015) and Olivia Laing's Crudo (2018) approach this challenge in their fictional explorations of lives marked by hyper-awareness of global events and the ensuing psychological and physiological effects. Both works, centered in opposite sides of the United States with Lerner's story based in New York and Laing's in Los Angeles, explore contemporary overstimulation ranging from mass media's flurry of updates, commercial barrages as well as an overwhelming influx of creative inspiration. The texts grapple with the division between the personal and the global selves as these impending crises cloud the narrators' minds. Their structure reflects this confusion and dislocation of the personal self, as the novels contain nonsequiturs, urban noise, and unrelated sections that have been pieced together deliberately. Through critically analyzing the novels alongside psychological studies of overstimulation in contemporary societies and Mikhail Bakhtin's concept of heteroglossia, this essay will investigate how Lerner and Laing capture the visceral effects of overstimulation through the narrative affordances of fiction.

In order to approach 10:04 and Crudo's venture into representing 21st-century life at the peak of the age of information, it is crucial to define the works within the realist tradition and how they stand apart from it. Originally a philosophical concept, the 19th-
\end{abstract}


century realist movement interpreted the search for truth into literary aesthetics. However, some critics suggest that the spirit of realism has "always existed" (Baron and Engel 9) in artistic pursuits as "mimesis" and the attempt to capture the world, conveying authenticity and verisimilitude without overbearing construction, is "certainly one of the impulses which lie at the origin of art and literature" (9). In the subsequent century, following an explosion of global awareness and cross-border social awareness, art and literature were struck by a "crisis of representation" (9), rushing in a wave of anti-realism. However, realistic movements towards literature and storytelling kept resurfacing, and in the contemporary age, there was a notable "shift from the textual acrobatics of postmodernism to a cautiously mimetic version of realism" (De Bruyn 951). De Bryun introduces this idea of "cautious" mimesis in relation to 10:04, given that while Lerner seeks to center his narrator in a familiar realm and encompass the totality of his existence in the world, the novel slightly deviates from realist tradition through his stylistic narrative construction. The artful structure of 10:04 sets a parallel between the narrator's overstimulation and submergence in social and political noise, alongside flooding of New York City and environmental collapse. In this way, "10:04 is not an example of traditional realism" but rather a readapted version closer to "'haunted realism', Lerner's term for unusually close attention to 'the merely real', may be more accurate - but it clearly does not overlook human drama" (De Bruyn 954). The novel "engages dialectically with the economic, cultural and material forces that produce reality today" (Boxall 46), seeking to evade the "limits to realist fiction [and] its focus on a narrow locale and set of characters [that] compresses distributed, global events" (Trexler 233).

The key to expanding realism's limited scope is to emulate Bakhtin's idea of heteroglossia, to have a novel that "speak[s] with many voices" (Johnson 124). The narratives of 10:04 and Crudo weaves in voices of media platforms, snippets of strangers' stories, and simulacrum of the cityscape that culminate in an almost incapacitating concern for the future. In this way, the "'realist' novel is capable of painting a remarkably broad canvas, clearly explor[ing] more-than-human networks" (De Bruyn 955) that go beyond existential and interpersonal relationships. While literary criticism of Laing's novel is still emerging, reviews of the work speak to its ability to readapt realism to the needs of 21 stcentury representation, as Crudo embodies "intensely personal and simultaneously global [...] concerns" and

"shouts to the vastness and the urgency of what it means to be alive, now" (Rhodes). Relating to stylistic structure, in Crudo's free-form stream of consciousness alongside Laing's claim that it had been written in "just seven weeks" (Rhodes), there is a deliberate narrative framework that layers Kathy's disparate existences to speak to the effects of living in current times. On one hand, there is the careless past that reminds readers of her namesake and "postpunk icon" (Rhodes) and on the other, the woman that attempts to embody the images of wealth and happiness she has encountered online. In both novels, while there is an emphasis on mimetically representing media-addled existence, the writers remain aware of the artifice of their work and channel it towards representing a chaotic multitude of stimuli, networks, and events. Just like the media they are capturing, they are 
constructing the way that the contemporary world must be viewed, through the lens of its chaos. Hence, the realist form which seems constricted to the individual experience, Laing and Lerner argue, can no longer carry the weight of contemporary life in the age of digital media.

Having grounded both works within their problematization of realist forms, their literary exploration of media saturation in everyday lives can be understood as an attempt to break out of the "narrow locale" to integrate the heteroglossic contemporary atmosphere. At the core of Lerner and Laing's depiction of reality revolves around the overabundance of stimuli in contemporary society that their characters, and audience, are faced with. Within social psychology, stimuli are defined through "diverse types of input such as sensory perception, information, emotion, communication, attachment, knowledge, culture, religion, and art" (Sar and Ozturk 199), all of which have been amplified by social media and the internet. At the outset of 10:04 and Crudo, written within a few years of each other, media coverage and knowledge exchange reach their peak as the political turmoil across the United States and abroad filters through a multitude of voices at once. After escalating over the past decade, individuals are afflicted by a "flooding of everyday awareness with irrelevant information" (210) that threatens the barriers between personal and external. In contemporary society, these forms of stimuli are ubiquitous to the extent that the ordinary individual is "encompassed in a cocoon of information in the form of image and sound" and living amongst a "stimulus glut" (St. Clair 49) that permeates every part of their life. The rapidly expanding presence of media has led up to the point that the individual's attention span cannot handle the stress of incoming stimuli and media channels face the challenge of the "widening gap between limitless media and limited attention" (Webster 4). The solution the media finds is to recalibrate their output into catchy, short headlines or clips to reel in overfed audiences (69), consequentially rewiring their attention spans. As a result, those living in contemporary spaces are affected in ways that have yet to be convincingly encapsulated in fiction.

Taking from Bakhtin's studies of linguistics, the value of language itself is at stake, which both novelists are attuned to. In his theory, Bakhtin posits that "language is a living thing, and as a living thing, it reflects and defines at the same time the various contexts in which it has been used", thereby "the word in language is half someone else's" (Johnson 123). Yet, when there is such a surge of information, that fraction is overpowered and as shown in the novels' protagonist, language feels too much like someone else's, endangering their sense of self in the cries of the world. Moreover, Bakhtin stresses that the "human language as a system of many voices" (128), but once those voices become disembodied or overabundant, such as with overpopulation and widespread media, the surge of information may reach a capacity, these novels seem to imply, that language becomes diluted and speech is impeded.

Lerner's 10:04 and Laing's Crudo endeavour to inhabit the headspace of a mediasaturated individual, experiencing an overexposure to knowledge, inspiration, and stimulus. The works are grounded in realism while gesturing to the dystopian and 
apocalyptic as impending doom hovers above the narrators' quotidian activities. On the one hand, 10:04 observes a life precariously wedged between two storms, led by an unnamed narrator whose worries about the future of the world clash with impending fatherhood. Touching upon similar anxieties, Crudo follows the news in the weeks preceding and following the narrator's marriage, with her tense responses to the media coverage serving as the narrative driving force. In these works, Lerner and Laing capture the contemporary "parade of stimuli" (Robson 79) and the anxiety rooted in its interruption of personal affairs.

Primarily, the texts illustrate such social and individual disruption by demonstrating the ubiquity of information sources that intrude upon the personal lives of the characters. In both works, the narrators are hyper-aware of the over-stimulating environments in which they inhabit, sharing an acceptance that the 'noise', not limited to sound but also images and symbols, is unavoidable. In a telling scene, Lerner's unnamed narrator is bombarded with information and audiovisual stimuli as he enters the public space of the subway:

"We helped edit a film on bonobos for the BBC; they're our closest relative and have no concept of sexual exclusivity."

"They say monogamy is an effect of agriculture. Paternity only started to matter with the transmission of property."

"Get tested for HIV today," said the poster on the D.

"But they do eat the young of other primate species."

"So why did you get married if you don't want kids?" We emerged onto the Manhattan Bridge; almost everyone checked email, texts. "You left without saying goodbye," Alex's said.

"Shine bright like a diamond," Rihanna sang through the earbuds of the girl beside me. (Lerner 50-51)

In this one-sided exchange, the narrator receives disparate pieces of information from all around him, all at once. Within the novel form, where image and sound cannot be represented in the organic overlapping way that they are experienced, the text manifests audiovisual disturbance through staccato dialogue. Moreover, the narrator is refused the chance to respond to any of the incoming stimuli, as a pop song played by a stranger cuts in after Alex's question. In deliberately refusing to attribute voices to their sources, Lerner creates a feeling of confusion. However, dismissing the information as a cacophony of irrelevant details would overlook the possibility that the comment about bonobos and paternity could be attributed to Alex as an attempt to normalize their agreement. In any case, bringing together the colliding disparate data serves as an experiment to gauge how the readers, contemporary individuals themselves, respond to scattered stimuli. Within that, the novel expects that individuals have become preconditioned to see patterns from random information as a way of making sense of a possibly arbitrary world. Moreover, the narrator's haphazard allusions to art, recalling Wallace Stevens at a restaurant, or science, concerned about the intelligence of the octopus he consumes, are another indication of the 
abundance of information he receives beyond the capacity to process any of it (St. Clair 3). On the whole, the narrator's role within the torrent of stimuli is of a receiver, allowing the influx of sights and sounds to pile upon him, almost passive. He reworks these encounters into his writing instead, attempting to digest his unsettling surroundings and test writing's capacity to make sense of it.

Reflecting on the overwhelming sensorium of living in the contemporary world, especially after being met with Roberto's concerns about Joseph Kony, he reflects on how overexposure to media can confuse one's configuration of the world. By emphasizing the bizarreness of the situation that an online video about the "Ugandan warlord" induces "an undocumented Salvadorean child's Brooklyn-based dream of a future wrecked by dramatically changing weather patterns" (Lerner 33), Lerner demonstrates the global scale on which the anxiety-inducing media operates, its accessibility making everyone feel eerily involved. The media interference in their lives forces them into a "condition brought on by the intuition of spatial and temporal collapse" (33) categorized by disorientation. Here, the narrator realizes that the overabundance of the public's knowledge manifests in a sense of impending doom, as he thinks to himself that "Roberto, like me, tended to figure the global apocalyptically" (33). The plethora of stimuli prefigures his apocalyptic reading of the world, one that is ingrained in the national consciousness. Regardless of age or background, the weight of the impending threat to national safety and an environmental crisis looms over the heads. Rather than being a mimetic "diagnosis of the present" (Watts 3 ), the encapsulation of the interrupted, turbulent experience serves as the narrator's troubled speculation about the future.

Thematically linked, Crudo exhibits the intrusion of external voices through the narrator's use of social media and her mobile phone, a portable, non-stop source of updates that marks the formidable presence of stimulus in modern life more directly. The novel opens with the chapter title, "ANYWAY", as if resurfacing from a bout of distraction which the reader comes to see as a result of the narrator being swept away by the torrent of social media. In contrast to Lerner's narrator, Laing's narrator, Kathy actively gathers information and "stalk[s] the internet" (Laing 109) out of her perceived "duty as a citizen [to] keep abreast of corruption" (156). Yet media theorists question whether consumers of digital media are ever really active agents in their consumption, as the only "powers" they really have are "to make meaning, to choose, to share" (Webster 24) with the only true way of "excerc[ising] their agency" being "through interpretation" (25). However, given the volume of information Kathy encounters, there is no way to sort through it all. Nevertheless, Kathy rationalizes her obsessive consumption of media, turning it into an obligation to "engage in "concurrent media use"" (6), absorbing the many disembodied voices around her. Her steadfast attitude towards consuming information is reflected in her imagination of herself as "a kind of drone [...] she liked the idea of herself up in the air with her compound eyes, hovering, gathering data" (Laing 25), affirmed by how she welcomes the interruption of significant moments in her life. Even on her wedding day, she claims "the main news was [Steve] Bannon" (126) and his resignation from office. Although "it had literally just happened" (126), everyone already has access to the 
information and it effectively disrupts the wedding reception. Emphasizing these interruptions, Laing paints a dismal portrait of the world of instantaneous updates in which any possibility of organic interaction is interrupted for seemingly no progressive outcome. In Crudo, the media's voice does not amount to any pivotal revelations, begging the question of the use of constant updates. Following this news, the retelling of the wedding is disrupted. Instead, Kathy reflects on vaguely related happenings, the removal of Confederate statues and the Earth "hotting up, going faster and faster" (127), until the reader finds her again, lying on her bed already embedded in the next chapter of her life. Both works' portrayal of disruption through stimuli also demonstrates the narrators' altered quality of attention and the way that the novelists are in turn, accommodating their contemporary reader's shortened attention span.

Responding to 10:04's apocalyptic note, Crudo illustrates a different kind of apocalypse wherein being perpetually fed information through mass media outlets creates a dangerous dependency that endangers morality, self-preservation, and emotional connection. These concerns are explored through Kathy's emotional state and negotiation of personal relationships, aided by the free indirect style of narration through which the reader bears witness to her breakdown. Her media-saturated lifestyle has ingrained in her a sense of impending doom, as she insists that "something was approaching. Kathy could not settle. She knew. She knew" (199), signifying her forecast of an impending calamity as a result of her consumption of news feeds. Faced with the neverending atrocity displayed to her and her belief that "the world might be about to end" (79), she abandons previous moralities for the belief that they should just "abolish not even gender but people" (106) as salvation is futile. Hope, a sentiment particular to human morality, is lost and she surrenders, furtively deciding that "since there'd be no end to it [...] the only thing I want is all-out war" (96). Although picturing the world "up in smoke" does not "lessen the anxiety" (84), at least then she can have a cathartic release, denied by the stream of upsetting information. Given her resolute desire for demise, her ability to sustain emotional connections to herself and others is severed as she indiscriminately argues with her husband. Although he is the "cleverest nicest most lovable man", she still responds like a "feral animal" just screaming a "noise without words" (119), almost literally unable to act in a socially accepted manner. In this way, the seemingly "interactive image" of social media can paradoxically become "anti-social or non-social in character" (Faucher 128) as it impairs Kathy's ability to prioritize issues directly within her reach. Evidently, what Kathy seeks in the endless feed of stimuli is manifold: a proclaimed fulfilment of her duty, distraction from her unfulfilling marriage, and an excuse for her undesirable compulsions.

Moving from the surface-level tensions between the external voices and personal lives of the narrator as the former interrupts the latter, the way that these works manifest the psychological and physical tolls of overstimulation can be investigated. The narrators illustrate the two types of responses in the face of "informational overload" (Robson 75), with Lerner's narrator afflicted with indecision, unable to act under the stress of knowing and Kathy being furtively embroiled in external conflict, acquiescing into the violent injustice. However, what they share is that they are both at a standstill, accepting an 
expected collective demise albeit in different ways. Their formal composition encapsulates the hysterics of living in the current times where there is no shortage of stimuli and the brain is overworked and moulded into a permanent state of crisis. In the case of Lerner's 10:04, the narrator minimizes himself within the retelling of his own life as he repositions himself within the larger devastation of the Anthropocene. His attunement to the environmental deterioration is a source of anxiety as he harbours the certainty that "the city would soon be underwater" (Lerner 243). Throughout the novel, this statement is repeatedly brought to the surface above all else as rather than worrying "about [their] literary careers", the narrator deems that he "should worry about being underwater" (324). Even after he and Alex successfully have sex, the narrator's mind is clouded with this fact as well as other anxiety-inducing stimuli such as "her mom's cells were dividing [and] the oceans [...] expanded as they warmed" (305). In the scale of things, he feels personally diminished, which is partly what he means when he asks, "Do you know what I mean if I say that what was most powerful about the experience was how it changed nothing?" (305), referring to the depth of his friendship with Alex that sex does not change their dynamic. However, the narrator also posits that although he accomplished something considerable, it did not change their collective doomed future. As a consequence of being inundated with reminders of his city's demise, the narrator is plagued with indecision, as he realizes the irresponsibility of bringing a child to this world yet also feels obliged to for Alex. Ultimately, the novel meets a premature end before any real decisions are made about his paternity, as if the narrator and work itself are postponing the inevitable.

As for Laing's venture into the effects of media saturation on the personal level, Kathy's responses to "chronic exposure to disproportionate stimuli" (Sar and Ozturk 210) are more overtly rendered. Obsessively "leaf[ing] through the internet" (Laing 83), Kathy's mood is completely at the whim of the latest headlines as they have an immediate effect on her, exacerbating her paranoia. Her belief that her exposure is part of her "duty" (156) diminishes the effect that it has on her body. Unlike Lerner's narrator, Kathy is not invested in any one global concern but rather indiscriminately seeks to care about everything all at once which is the expansiveness that social media affords, and encourages. Parallel to 10:04's looming doom, Crudo encapsulates how the barrage of external voices informs the sense of dread as Kathy feels "each day [...] something creeping nearer" (199), ultimately growing "resigned" (96) to the inevitability of doom. Through the course of the novel, this exposure becomes debilitating as Kathy develops physical markers of her anxiety about the future. Losing sleep and dealing with "perpetual headaches" (194), she exhibits the psychological stress that trauma theorists identify with the media's "interruptions of consciousness" (Sar and Ozturk 210). While watching "smiling men policing women's bodies smiling men deporting immigrants", Kathy is infuriated to the extent of physical pain as "her back hurt, her spine hurt" (184). The direct correlation between her psychosomatic condition and her exposure to the media is represented through the disintegrated form of the narrative, as the incoming stimuli are listed without the separation of commas, inducing a feeling of chaos. Her way of responding to the bombardment is writing "the worst things she can imagine [...] letting 
herself be raped and beaten" (84), demonstrating that her overexposure to devastation has conflated global suffering with her own. Among the healthier coping mechanisms she uses to deal with her overstimulated mind is to "itemize the things" (83) around her, the act of describing the objects around her as a way of making sense of the frenzied world. This procedure mimics Laing's writing process, itemizing contemporary reality in an uninhibited way as suggested by the title which translates to 'raw'. Just like Kathy, Laing does not permit herself the time to process her observations of the rapidly changing world as Crudo is famously not edited or reworked, lending itself to a more closely authentic realization of life in contemporary times. On a larger scale, by threading global crises through the characters' quotidian lives, both works place them on equal levels of narrative significance. Such capacity to place both stories on the same level in that way is an affordance indebted to the novel form which allows that the personal trouble of Lerner's narrator and New York's demise as well as Kathy's relationships and tense international relations to be held in close regard.

Building off this point, both texts investigate the blurring of boundaries of personal identity and external influence, while the characters negotiate the loss in distinctively different ways. As informed by psychology, the "threat of external chaos" which the characters are perennially engulfed in, "triggers dissociative fears of internal (i.e., individual) chaos" (Sar and Ozturk 210). Consequently, this dissociation disrupts their identification with their own voice, lost in the cascade of other "clutter" (Robson 72) and unsettling stimuli. Zoning in on the collapse of personal and external, the authors use narrative distancing techniques to illustrate the current climate's denial of intimacy and sense of self. Principally, 10:04 embodies the dissociative state through its elusive narrator. Narrating through the distant third-person mode refuses the certainty of the 'I', denying the "incredible intimacy" of the first-person pronoun in favour of the "incredible distance" (Foyles 00:05:39-00:05:43) of the unnamed narrator, always one degree removed behind the screen of incoming stimuli. Writing within the autofiction mode pushes the boundary of subjectivity as the narrator is filtered through layers of identity- as Lerner himself, the narrator, the character- trickling down until he is a vague silhouette. In turn, the narrator is especially receptive to the external voices around him, becoming intertwined with the global occurrences and creative stimuli. Crucially, his heart condition is overlaid by the impending storms, denoted in the parallels drawn between the applications tracking Irene and "the same technology [...] utilized to measure the velocity of blood flow through [his] arteries" (Lerner 28). Moreover, during Alex's ultrasound, he sees "the image of the coming storm, its limbs moving in real time" (233), confusing the fetus with the image of the hurricane. As his body takes on the shape of the environmental crisis, Lerner demonstrates how due to the level of interference, the narrator cannot separate himself from the global catastrophe.

Comparably, Crudo explores the collapse of the personal-external boundary through its narrative composition as an experimental rambling, driven by the sporadic tempo of political events rather than personal milestones, such as Kathy's marriage. The indirect style of narration filters the external stimuli exclusively through Kathy's 
perspective, yet rather than interpreting this as solipsistic, it manifests how deeply she internalizes the world around her. At once, Kathy feels removed from herself, believing herself to be "not real" especially "around other people" (209) as she cannot distinguish her interests and history from the torrent of voices around her. Her referral to political figures by their first names when she recalls an "essay on Ivanka and Jared" (Laing 156) indicates the media's capacity to create an illusion of familiarity, which Kathy readily accepts. Moreover, Laing blurs the boundaries between the ' $\mathrm{I}$ ' and the global other by writing in the third person through the narrating voice of Kathy Acker, herself reluctant to refer to herself personally. Laing writes, "Kathy, by which I mean I" and repeats, "Kathy, by which I mean I" (8), denying any intimacy with the reader as the narrator hesitates between referring to themselves in the first person or the distant third. This dissociation extends to the narration of events as Kathy shares, "I was angry. And then I got married" (10), in which the choppy paratactic sentences delineate the disconnection Kathy feels from her thought process. Kathy allows virtual experiences to bridge the gap of her own, as "she hadn't had a husband before but she knew how it worked" (10). Moreover, the media seemingly gives her insight into what a woman's life should be like, prefacing her unhappiness when she encounters it firsthand. This hands-off approach is juxtaposed with her relationship to trivial matters such as "Wordsworth and Europe" about which "Kathy had really quite passionate feelings" (30), to the point of being embroiled in an argument. The global becomes explicitly personal as she speculates that "if it was happening to someone, it being unspeakable violence, how could she be happy" (199), signalling her emotional entanglement in external occurrences. However, rather than being interpreted as means towards fostering empathy, the exposure to such violence is a "splinter in her own corporeality" (199), detrimental to her wellbeing. Fundamentally, to Kathy, separating her real life and the political is not just irresponsible, but impossible as the political is deeply interwoven into her personal life.

However, it is not just climate change and political calamity that screens onto the narrators' physical and mental selves, as the narrators also inhabit other people's voices and experiences. In this way, both texts draw on Bakhtin's concept of heteroglossia, conscious of the fact that "utterances are never uttered in a void [...] but are always connected to other voices" (Johnson 135). Particularly, 10:04's narrator experiences this inhabited sense of overstimulation in the way that he is hyper-aware of his referentiality. The complicated history of words haunts the narrator in the same way that the collapse of the real world does, sending the narrator into an existential crisis. His sprialing is evident in the clinic as he is sending in sperm samples and the narrator humurosly falls into Beckettian role while comically going back and forth from the sink to his chair, his mind too clouded to move with full intention. Most significantly, his more deliberate attempts to embody a "would-be Whitman of the vulnerable grid" (Lerner 10), emulating the poet's style to the point of allowing his work to subsume him entirely in Marfa, exhibits his overwhelmed state of influence. Feeling the weight of every word being "half someone else's" (Johnson 125), the narrator doubts his own contributions. Turning to Whitman, he embodies the poet's spirit of writing "relentlessly to the future" (LRB Lerner 42), through 
deliberate vagueness in his references to timely events such as the Occupy movement and the storms in an attempt to ensure the relevancy of his work, no matter what current of information comes along. In mapping out Lerner's creative influence and subsumption of other voices critiques the contemporary condition, where everything is available at once and thereby, a new form must arrive that encapsulates the complicated patchwork of voices. In the end, Lerner remains optimistic as his work depicts how "a moment of anticipated danger seems to open up the future" (Bilmes 1093) in which human mental facilities, bodies, as well as art, can grow to be more than "stylized despair" (Lerner 140) and adapt to the overstimulating environments.

Meanwhile, Laing's work also affirms the sentiment that every thought or piece of creative work in the contemporary world of mass media becomes a palimpsest of influences. The most apparent reference is the American experimental novelist, Kathy Acker, whom Laing uses as an avatar for the contemporary woman. While anachronistic, weaving Acker into the current moment reveals the cyclical nature of society, the same concerns that once concerned her such as terrorism and women's agency over their bodies are still up for debate. Additionally, in creatively drawing from Acker's life, Laing perpetuates the exchange of inspiration that spans decades as Acker herself blatantly borrowed from Charles Dickens for her novel, Great Expectations. Another evident example of Laing's borrowing of language is the lengthy list of sources she provides at the novel's conclusion. Crudo also explores referentiality as Kathy asserts that, "it's all material, I mean what is art if it's not plagiarising the world?" (Laing 214), calling attention to the incredible access to material that Kathy and other contemporary web-dwellers have. Deciding to use a historical figure acts as both a nod to digital media 'avatars', as well as a deliberate rejection of narrative expectations as the narrator is not Laing and not wholly Acker. Rather, in "writing, [Kathy] can be anyone. On the page, the [she] dissolves, becomes amorphous, proliferates widely" (221), thus equating literature with the media for its wide dissemination while also alluding to the dissolution of identity. Laing cites the confusion of the personal, global, and creative influences as quintessentially contemporary, as "to write from a stable point of view meant losing the feeling of chaos and perpetual disruption" (Kraus) that she felt within her media-saturated lifestyle. Essentially, Crudo illustrates how identity is wholly confused by the staggering layering of influences. Yet, Laing takes a divergent stance on literature's future, feeling that literature may crumble under the weight of depicting the barrage of material. Formally, her writing technique of uninhibited, unedited writing demonstrates her belief that the contrived works of the past cannot reflect the pace and sentiment of current times.

In essence, Lerner and Laing channel the tumultuous experience of contemporary over-exposure to information and stimuli by foregrounding the interruptions to daily life and unsettling narrative expectations. Their ventures into the overstimulation of globally connected citizens and web-dwellers are demonstratively not merely mimetic efforts but rather inquiries into the individualized identity that persists over the interruptions of the political, commercial, and creative stimuli. Above all, they beg the question about the future of the novel in light of the changing mental capacities and social pace, reaching 
Amal Alshamsi, Contemporary Overstimulation in the Age of Information: The Blurring of The Personal and Political in Ben Lerner's 10:04 and Olivia Laing's Crudo

disparate conclusions.

\section{Works Cited}

Baron, Christine, and Manfred, Engel. Realism/Anti-Realism in 20th-Century Literature, BRILL, 2010. ProQuest Ebook Central, https://ebookcentral.proquest.com/lib/ed/detail.action?docID=587906

"Ben Lerner: No Art $\mid$ Poetry, fiction, criticism, fiction, poetry" YouTube, uploaded by Foyles, November 1, 2016, https://www.youtube.com/watch?v=8PGkC6e855Q.

Boxall, Peter. The Value of the Novel. New York, NY, USA: Cambridge University Press, 2015.

Bilmes, Leonid. "'An Actual Present Alive with Multiple Futures': Narrative, Memory and Time in Ben Lerner's 10:04." Textual Practice, vol. 34, no.7, 2020, p.1081102. https://doi.org/10.1080/0950236X.2018.1515789

De Bruyn, Ben. "Realism $4^{\circ}$. Objects, Weather and Infrastructure in Ben Lerner's 10:04.” Textual Practice, vol. 31, no. 5, Routledge, 2017, pp. 951-71, https://doi.org/10.1080/0950236X.2017.1323490

Faucher, Kane. "The Network Spectacle." Social Capital Online: Alienation and Accumulation, vol. 7, University of Westminster Press, London, 2018, pp. 109134. JSTOR, www.jstor.org/stable/j.ctv5vddrd.9

Genders, Paul. “Olivia Laing: CRUDO.” TLS. Times Literary Supplement (1969), no. 6021-6022, NI Syndication Limited, 2018, p. 42.

Johnson, Marysia. A Philosophy of Second Language Acquisition, Yale University Press, 2003. ProQuest Ebook Central, https://ebookcentral.proquest.com/lib/ed/detail.action?docID=3419955.

Kraus, Chris. "Becoming Kathy Acker: An Interview with Olivia Laing." The Paris Review. 13 Sept. 2018.

Laing, Olivia. Crudo: A Novel. W. W. Norton \& Company, 2018. Kobo edition.

Lerner, Ben. 10:04 : A Novel. Farrar, Straus and Giroux, 2014. Kobo edition.

---. 'Diary.' London Review of Books, vol.37, no.12, 2015, 42-43.

Miller, Michael F. "Why Hate the Internet?: Contemporary Fiction, Digital Culture, and the Politics of Social Media." The Arizona Quarterly: A Journal of American Literature, Culture, and Theory, vol.75, no.3, 20019, p.59-85. https://doi.org/10.1353/arq.2019.0017

Robson, Gregory J. "The Threat of Comprehensive Overstimulation in Modern Societies." Ethics and Information Technology, vol. 19, no.1, 2017, p.69-80. https://doi.org/10.1007/s10676-016-9414-0

Rhodes, Emily. "Ways of escape. (Olivia Laing's 'Crudo')." Spectator, vol. 337, no. 9905, The Spectator Ltd. (UK), 2018, p. 32.

Sar, Vedat, and Erdinc Ozturk. "Stimulus deprivation and overstimulation as dissociogenic agents in postmodern oppressive societies." Journal of Trauma \& Dissociation, $\quad$ vol. $14, \quad$ no.2, 2013, p. 198-212. https://doi.org/10.1080/15299732.2013.724346

St. Clair, Michael. So Much, So Fast, So Little Time: Coming to Terms with Rapid Change and Its Consequences, ABC-CLIO, LLC, 2011.

Trexler, Adam. Anthropocene Fictions: The Novel in a Time of Climate Change. University of Virginia Press, 2015. 
Watts, Steven. "An Eerie Cacaphony: Forms of the Collective in Occupy Novels." $C 21$ Literature 8.1 (2020): C21 Literature, vol.8, no.1, 2020, p.1-28. https://doi.org/10.16995/c21.1438

Webster, James G. The Marketplace of Attention : How Audiences Take Shape in a Digital Age, MIT Press, 2014.

\section{The Authors}

\section{Amal Alshamsi}

University of Edinburgh, UK

Email: aas1005@nyu.edu

\section{The Article}

Date Sent: 27/10/2021

Date Revised: 02/12/2021

Date Accepted: 04/12/2021 